\title{
Mercury content in different media related to the use of dental amalgam
}

\author{
Vladimir Panov \\ Department of Conservative Dentistry and \\ Oral Pathology, Faculty of dental medicine, \\ Medical University -Varna;
}

\begin{abstract}
All types of dental amalgams contain mercury, which partly emits mercury vapor. Dental amalgams corrode after being placed. When we rub or polish dental amalgam, droplets rich in mercury are formed on the surface, showing that mercury is not strongly bonded to the base or alloy metals.

To determine the mercury content in various fluids related to the use of dental amalgam we investigated sewage samples, amalgam obturation flushing, amalgam removal flush, amalgam polishing flush, water containing residual unused new amalgam left for two weeks, and saliva of patients with more than four old amalgam obturations. We applied Atomic coupled plasma emission spectral analysis.

From our studies we can conclude that the least amount of free mercury is detected in the sewage and mouthwash when an amalgam is being placed, followed by saliva of patients with more than 4 obturations, water in which amalgam has been kept for two weeks, mouthwash when amalgam is removed, and the biggest amount of mercury is released when polishing old amalgam obturations. The most dangerous to human health is polishing old obturations, followed by removal, while the least amount of mercury is released when such obturations are placed. Our research shows that if you are a dentist, even if you do not use dental amalgam, you are exposed to mercury vapor when you are working in the mouth of a patient with this material.
\end{abstract}

Keywords: Mercury, dental amalgam, mercury content, sewage, saliva 


\section{Introduction}

For more than 200 years dental amalgam has been a reliable restorative material because of its durability, longevity, effortless handling and low cost. Since its creation, there have been many disputes about its banning due to discharges of mercury in its processing. Although we have new materials and techniques we still use this material (1). In many countries, including Bulgaria, the silver amalgam is still widely used to restore damaged teeth, in about half of the population $(2,3)$.

Mercury $(\mathrm{Hg})$ has been identified as one of the most toxic nonradioactive materials known to man. Although mercury is a naturally occurring element, anthropogenic mercury is now a major worldwide concern and is an international priority toxic pollutant (4).

Mercury, in its various forms, has different pathways of metabolism and toxicity. The critical organ is this one in which changes are first developed. For inorganic $\mathrm{Hg}$ salts, the kidneys and the central nervous system are the critical organs and for organic $\mathrm{Hg}$ compounds and metallic $\mathrm{Hg}$, the central nervous system is most affected.

All types of dental amalgams contains mercury, which partly emits mercury vapor. Dental amalgams corrode after being placed. When we rub, wear or polish dental obturations, droplets rich in mercury are formed on the surface, showing that mercury is not strongly bonded to the base or alloy metals. Low and high copper amalgams undergo a transformation process for several years after placement, resulting in a substantial reduction in mercury content, but there exist no limit for maximum allowed emission of mercury from dental amalgams (5). Urine mercury remains the most practical and sensitive means of monitoring low level occupational exposure to inorganic mercury(6).

Numerous studies have reported neurobehavioural effects in dental personnel occupationally exposed to chronic low levels of mercury. $\mathrm{Hg}$ exposure from dental work may also induce various chronic conditions such as elevation of amyloid protein expression, deterioration of microtubules and increase or inhibition of transmitter release at motor nerve terminal endings (7).

Along with the toxicity of mercury, various conditions can be observed in the mouth after the use of this metal. Oral lichenoid lesions caused by contact with dental amalgam are difficult to distinguish clinically or histologically from other lichenoid lesions or from idiopathic oral lichen planus. Oral pathogalvanism occurs when various metal alloys are simultaneously present in the liquid medium of the mouth with a local or systemic effect. A variety of reactions and disorders in the tissues in the maxillofacial area have been described, associated with the presence of dental amalgam. The lesions are usually asymptomatic, but rarely patients report pain or tenderness when eating hot or spicy food.

Electrically charged metal objects in the mouth can cause complaints of metallic taste, paraesthesia, tingling, burning, various inflammatory processes but presence of pathogalvanism with elevated values is seldom $(8,9)$. The rare cases of allergic reactions in about $4 \%$ of tested patients is explained with the large oral tolerance and adaptive abilities of the oral cavity (10). 


\section{Aim}

To determine the mercury content in various fluids related to the use of dental amalgam.

\section{Material and methods}

Quantities of mercury are investigated in 24 sewage samples, amalgam obturation flushing, amalgam removal flush, amalgam polishing flush, water containing residual unused new amalgam left for two weeks, and saliva of patients with more than four old amalgams obturations.

The method used was Atomic coupled plasma atomic emission spectral analysis (ICP-OES). We separated the solution by filtration and determined mercury in it. All samples were acid decomposed with Aqua regia ( $3 \mathrm{ml} \mathrm{HCl}+1 \mathrm{ml} \mathrm{HNO3)}$ in a microwave mineralization system MLS 1200 Mega. The Prodigy 7 model of inductively coupled plasma atomic emission spectrometer (ICP-OAS) was used for filtration. All probes were determined at the Agrarian University - Plovdiv, Laboratory for Instrumental Methods.

\section{Results}

When examining the level of mercury in dental wastewater, we found an average of $1.27 \mathrm{mg} / \mathrm{l}$ in filtrate; $7.19 \mathrm{mg} / \mathrm{l}$ in sediment, and an average of $4.23 \mathrm{mg} / \mathrm{l}$ for all samples. The amount of free mercury is between 5 and 7 times higher in the sediment than in the filtrate.

Table 1. Mercury content ( $\mathrm{mg} / \mathrm{l})$ in different media

\begin{tabular}{|l|l|l|l|}
\hline Media & Filtrate $\mathrm{mg} / \mathrm{l}$ & Sediment $\mathrm{mg} / \mathrm{l}$ & Average for samples \\
\hline Sewage & 1.27 & 7.19 & 4.23 \\
\hline Wash when inserted & 0.45 & 8.20 & 4.33 \\
\hline Wash when removed & 2.81 & 13.99 & 8.4 \\
\hline $\begin{array}{l}\text { Flushing during } \\
\text { polishing }\end{array}$ & 3.25 & 23.48 & 13.62 \\
\hline $\begin{array}{l}\text { Water that contained } \\
\text { the remains of an } \\
\text { unused new amalgam }\end{array}$ & 4.05 & 12.27 & 8.16 \\
\hline Saliva & 1.00 & 10.12 & 5.56 \\
\hline
\end{tabular}


When the amalgam was placed, in the mouthwash the mercury values were 0.45 in the filtrate, 8.2 in the sediment with an average of $4.325 \mathrm{mg} / \mathrm{l}$. The values in the filtrate are about 18 times lower than the ones in the precipitate.

In water when removed there are $2.81 \mathrm{mg} / \mathrm{l}$ in the filtrate and $13.99 \mathrm{mg} / \mathrm{l}$ in the sediment or an average of $8.4 \mathrm{mg} / \mathrm{l}$ when removing obturations. Here, the values in the filtrate are 5 times lower than in the precipitate.

When polished, the data indicate that the filtrate contains $3.25 \mathrm{mg} / \mathrm{l}$ and the precipitate $23.48 \mathrm{mg} / \mathrm{l}$. The average is 13.62, and the amount of free mercury is about twice and a half higher in the sludge.

The samples we have tested show that in water in which the excess of new, unused amalgam is left for 2 weeks the values are just above $4 \mathrm{mg} / \mathrm{l}$ in the filtrate and about $12 \mathrm{mg} / \mathrm{l}$ in the precipitate.

In saliva of patients with more than 4 obturations, we find $1 \mathrm{mg} / \mathrm{l}$ mercury in the filtrate and more than 10 in the precipitate, with an average of about $5.5 \mathrm{mg} / \mathrm{l}$.

These results show that amalgam administration releases a quantity of mercury slightly smaller than is contained in the sewage flowing from the dental unit. The values in sewage and flush when inserted are almost the same.

Twice as much mercury content is detected when old amalgam obturations are removed.

When polishing old obturations, the release of mercury is even higher - three times more than in placement, sewage, and significantly higher than during the removal of old obturations.

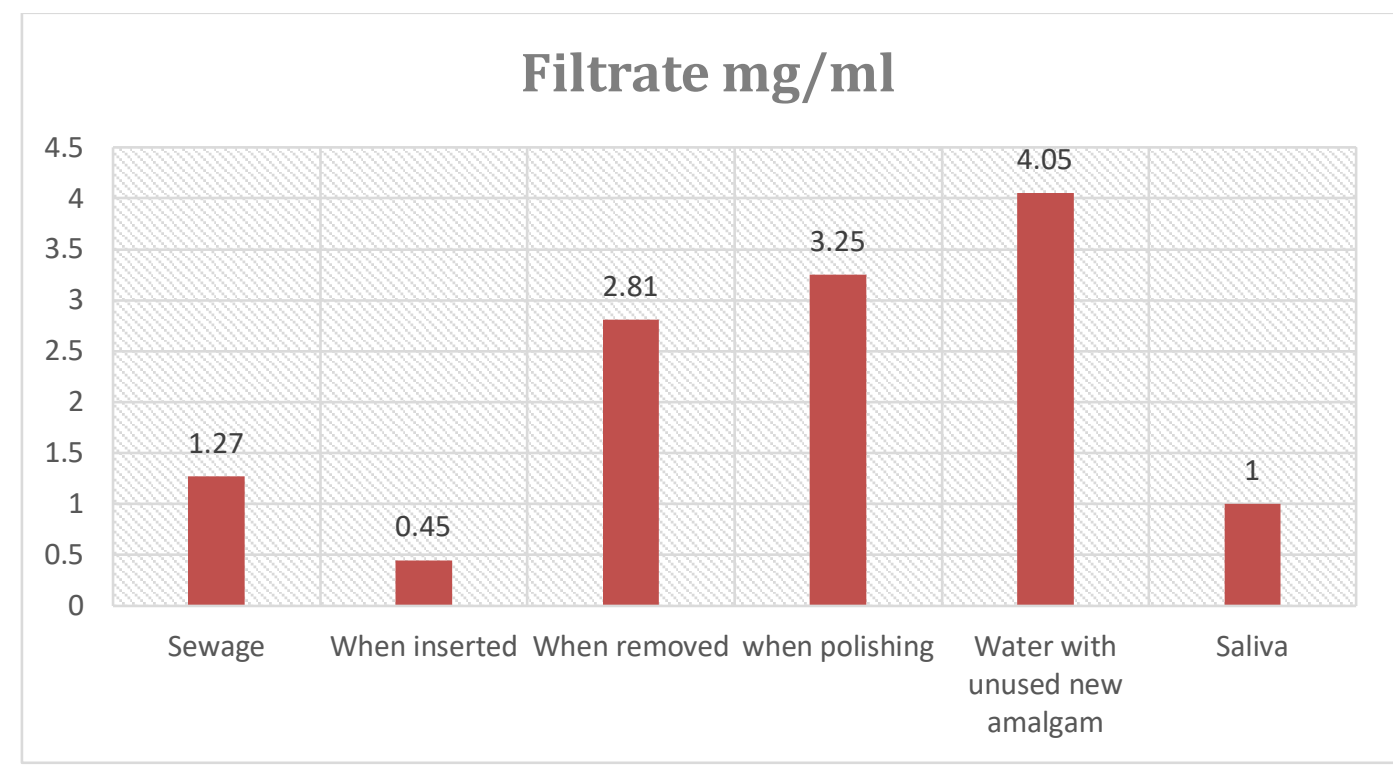

Figure 1. Amount of mercury in samples of filtrate 


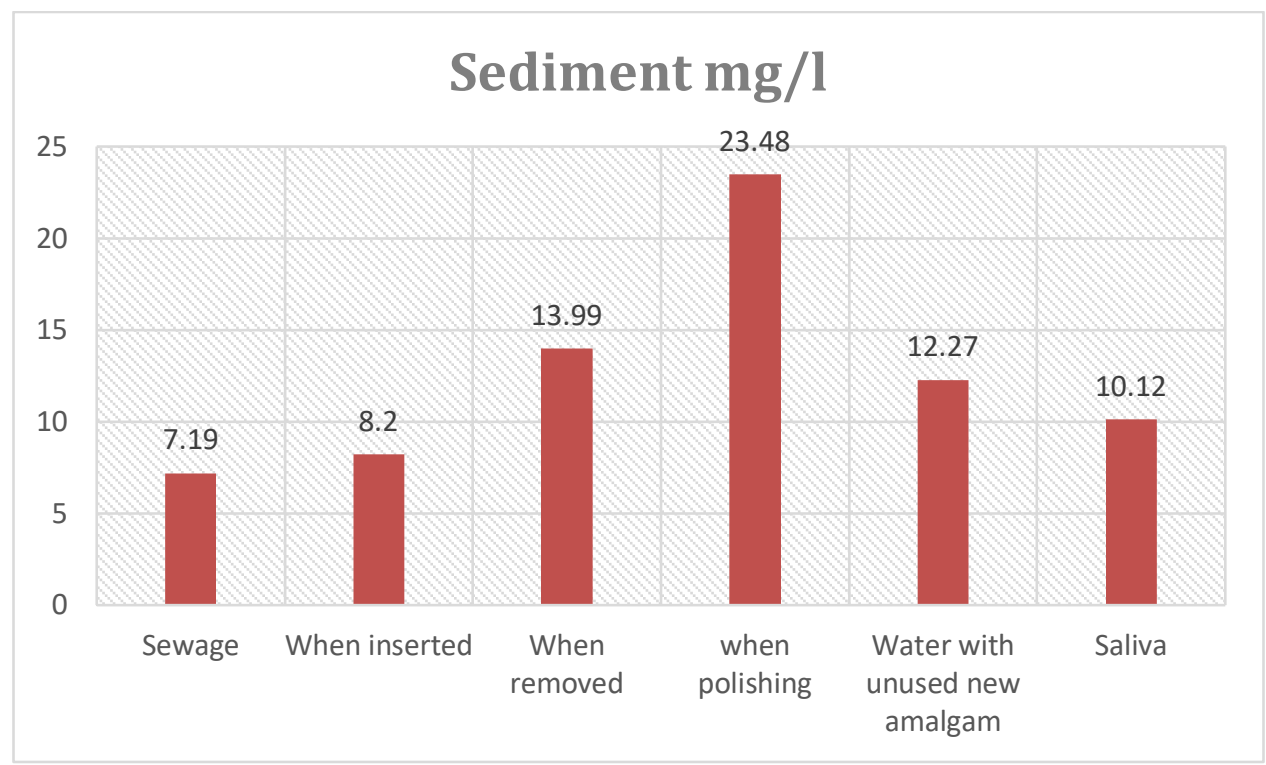

Figure 2. Amount of mercury in sediment samples

In water in which unused amalgam pieces are stored, the amount of free mercury is almost equal to that of removal and twice as high as sewage and flushing from amalgam placement.

In saliva of patients with more than 4 old obturations, the amount of free mercury is higher than in sewage and flushing from placement, but lower than the levels at removal and polishing.

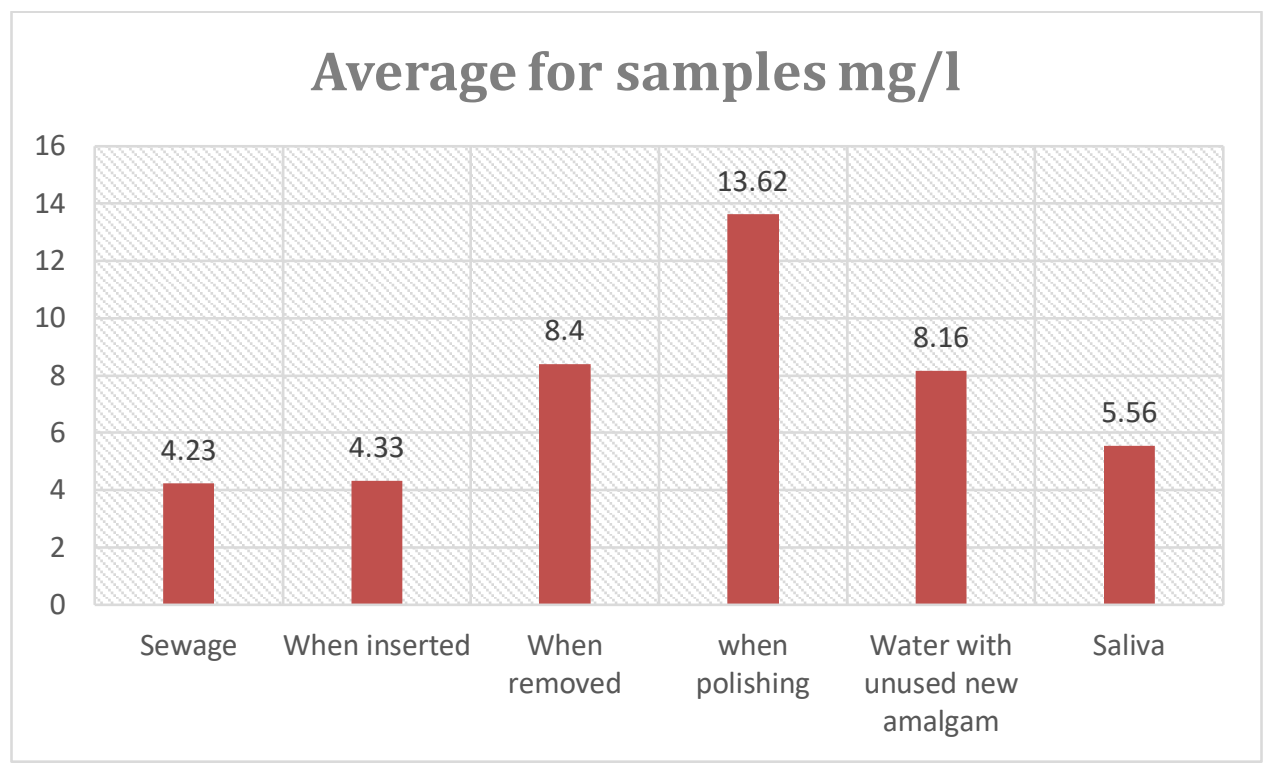

Figure 3. Average amount of mercury in samples 


\section{Conclusion}

From our studies we can conclude that the least amount of free mercury is detected in the sewage and mouthwash when placed, followed by saliva of patients with more than 4 obturations, water in which there was amalgam for two weeks, mouthwash when removed, and the largest amount of mercury is released when polishing old amalgam obturations. Most dangerous to human health is polishing followed by removal, and the smallest quantity of mercury is released when such obturations are applied.

Our research shows that if you are a dentist, even if you do not use dental amalgam, you are still exposed to mercury vapor when you are working in the mouth of a patient with this material.

\section{References}

1. Panov VI, M Markova, History of dental amalgam, Varna Medical Forum, 2016, 5 (1), 119-123.

2. Markova M, Panov Vl, Georgiev G, Vicheva Z, Dental amalgam - clinico-epidemiological aspects, Varna Medical Forum, 5(2), 2016, 210-213.

3. Panov Vl, Changes in the Oral Cavity and Common Diseases, 2016, Post-Doctoral thesis, Varna, 291.

4. Jirau-Colón H, González-Parrilla L, Martinez-Jiménez J, Adam W, Jiménez-Velez B. Rethinking the Dental Amalgam Dilemma: An Integrated Toxicological Approach, Int J Environ Res Public Health. 2019 Mar 22;16(6).

5. Ulf G. Bengtsson Lars D. Hylandercorresponding, Increased mercury emissions from modern dental amalgams, Biometals. 2017; 30(2): 277-283.

6. Morton J, Mason HJ, Ritchie KA, White M. Comparison of hair, nails and urine for biological monitoring of low level inorganic mercury exposure in dental workers. Biomarkers. 2004 JanFeb;9(1):47-55.

7. Bjørklund G, Hilt B, Dadar M, Lindh U, Aaseth J, Neurotoxic effects of mercury exposure in dental personnel. Basic Clin Pharmacol Toxicol. 2019 May;124(5):568-574.

8. Panov $\mathrm{VI}$, Adverse reactions in the mouth when using dental amalgam, Varna Medical Forum, 5(1), 2016, 77-81.

9. Panov VI, Markova M, Corrosion potential in oral cavity, Medinform, 2018;5(1), 750-759.

10. Balcheva M, Panov Vl, Krasteva A, Markova M. Allergy to dental amalgam, Medinform, 6(1), 2019, 968-974.

\section{Corresponding author:}

Vladimir Panov,

Faculty of Dental Medicine,

Department of Conservative Dentistry

and Oral Pathology,

Medical University - Varna,

email: vladimir.panov@mu-varna.bg 